\title{
PENGARUH AKSESIBILITAS, IT DAN AKSI KOMPETITIF PADA USAHA MIKRO KECIL DAN MENENGAH
}

\author{
Zeis Zultaqawa' ${ }^{1}$ Mohammad Benny Alexandri², Muhammad Rizal ${ }^{3}$, \\ Nenden Kostini ${ }^{4}$, Muhammad Donie Aulia ${ }^{5}$ \\ Business Administration, Universitas Padjadjaran, Bandung, Indonesia \\ zeiszul@gmail.com¹, bennyalexandri@yahoo.co.id², rizal.unpad@gmail.com³ \\ kostini@yahoo.co.id ${ }^{4}$, donie.aulia@gmail.com ${ }^{5}$
}

\begin{abstract}
ABSTRAK
Tujuan dari penelitian ini adalah untuk mengetahui bagaimana aksesibilitas dan infrastruktur teknologi informasi berdampak pada tindakan kompetitif sektor usaha kecil dan menengah di industri pakaian di Kabupaten Bandung, Indonesia. Sampel diambil dengan teknik random sampling. Survei dilakukan pada 110 industri pakaian. Data diproses menggunakan Structural Equation Modeling-Partial Least Squares. Temuan menunjukkan bahwa aksesibilitas memiliki efek positif pada tindakan kompetitif dan infrastruktur teknologi informasi memiliki efek positif pada tindakan kompetitif. Penelitian ini menunjukkan bahwa aksesibilitas dan infrastruktur teknologi informasi dapat menciptakan tindakan kompetitif dalam industri pakaian di Kabupaten Bandung, Indonesia. Makalah ini menyoroti perlunya perusahaan untuk mengoptimalkan sumber daya dan kemampuan perusahaan dalam lingkup manajemen strategis, tidak hanya dalam menciptakan tindakan kompetitif tetapi juga untuk meningkatkan pertumbuhan ekonomi regional. Orisinalitas / nilai dari penelitian ini adalah teknologi informasi dan komunikasi adalah studi yang sedang berkembang dari literatur manajemen strategis berdasarkan teori pandangan berbasis sumber daya, infrastruktur teknologi informasi dapat menciptakan tindakan kompetitif bagi perusahaan untuk dapat bersaing dengan perusahaan sejenis lainnya. industri.
\end{abstract}

Kata kunci: Aksesibilitas, infrastruktur TI, Tindakan kompetitif, UKM, Industri pakaian

\section{PENDAHULUAN}

Peran Infrastruktur Teknologi Informasi (TI) pada pertumbuhan ekonomi dewasa ini menjadi topik menarik untuk diteliti (Colin, Galindo, \& Hernández, 2015; Erumban \& Das, 2016; Salahuddin \& Alam, 2016; Vu, 2013). Farhadi et al. (2012) mengusulkan agar perusahaan membangun perusahaan yang siap menghadapi Techno-Business Environment untuk mampu bersaing secara global. Saran tersebut sesuai dengan kondisi lingkungan bisnis saat ini dimana kemajuan TI sedang berkembang pesat, sehingga TI menjadi faktor baru dalam menciptakan Keunggulan Kompetitif bagi UKM (Apulu \& Latham, 2009; Jung, Na, \& Yoon, 2013; Li, 2009). Davenport \& Linder (1994) juga menyarankan bahwa faktor Infrastruktur TI menjadi senjata persaingan yang baru, dan juga menjadi strategi yang efektif untuk mencapai keunggulan bersaing.

World Bank (1994) membagi infrastruktur menjadi 3 (tiga) kategori berdasarkan fungsinya, yaitu:
(1) Infrastruktur ekonomi. Infrastruktur ekonomi adalah pembangunan fisik yang menunjang aktivitas ekonomi: public utilities (tenaga listrik, teknologi informasi, air, sanitasi, gas), pekerjaan umum atau public work (jalan, bendungan, kanal, irigasi, dan drainase), dan sektor transportasi (jalan, rel, pelabuhan, lapangan terbang dan sebagainya); (2) Infrastruktur social. Infrastruktur social adalah: infrastruktur yang mengarah pada pembangunan manusia dan lingkungannya seperti pendidikan, kesehatan, perumahan, dan rekreasi; (3) Infrastruktur administrasi merupakan infrastruktur dalam bentuk penegakan hukum, kontrol administrasi dan koordinasi. Pertumbuhan pengguna TI di Indonesia menunjukkan kemajuan yang signifikan. Hal tersebut sesuai dengan data yang ditunjukan oleh Asosiasi Penyelenggara Jasa Internet Indonesia (APJII). Hingga pada tahun 2017 terdapat 143,26 juta orang yang menggunakan TI berupa jaringan internet. 


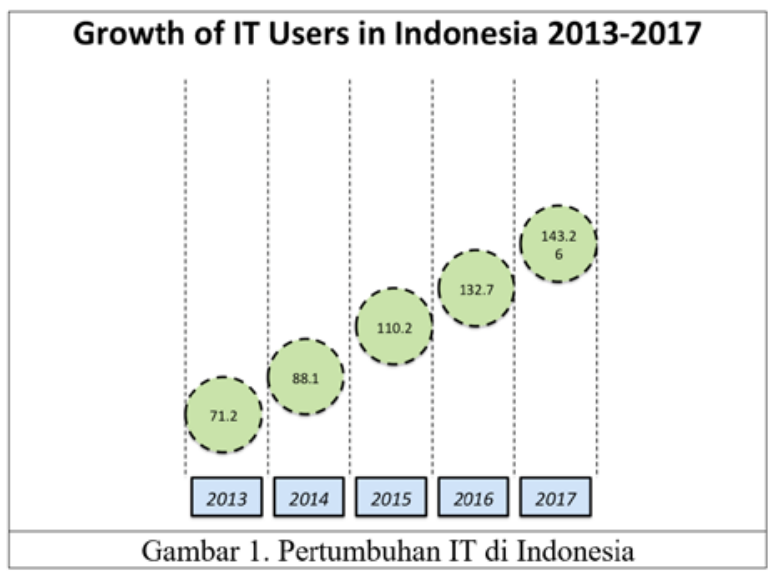

Pemanfaatan TI sebagai sumber daya perusahaan pada UKM di Indonesia menunjukan pertumbuhan yang tinggi. Euromonitor Internasional mencatat bahwa penjualan online Indonesia lebih tinggi dari Thailand dan Singapura. Pasar $e$ commerce Indonesia diyakini berpeluang untuk tumbuh semakin besar. Hal tersebut didukung dengan jumlah penduduk dan tingkat produk domestik bruto (PDB) terbesar di ASEAN. Statista International mencatat rata-rata pertumbuhan tahunan penjualan online Indonesia selama 2014-2020 terus tumbuh (Gambar 1.2).

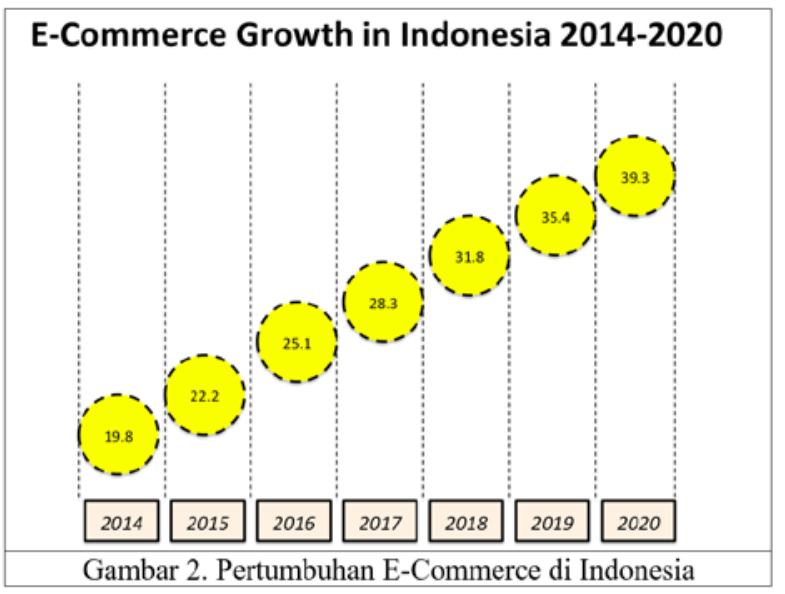

Kemudian teknologi akses jaringan pada transaksi online yang digunakan pada transaksi online untuk pembeli perorangan menunjukan bahwa mobile broadband wireless (3G, LTE/4G) paling banyak digunakan (Gambar 1.3). Hal tersebut berarti perkembangan teknologi mobile phone berpengaruh pada dinamika bisnis. Kementerian Koperasi dan UKM (2017) mencatat bahwa pelaku UKM yang sudah memanfaatkan teknologi digital seperti e-commerce sudah mencapai 3,79 juta UKM (Deputi Pemasaran Kementerian Koperasi dan UKM, 2017).

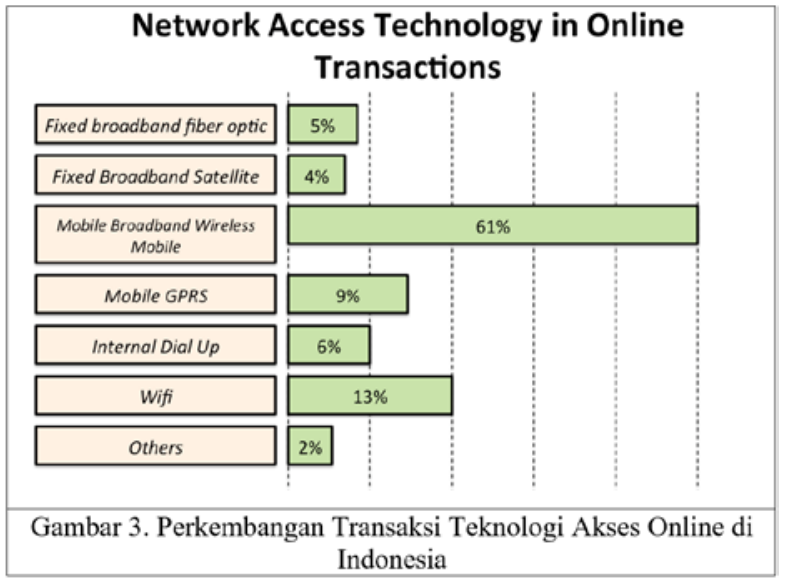

UKM di Provinsi Jawa Barat memiliki peran yang sangat penting terhadap perekonomian. Berdasarkan Gambar 4, bahwa UMKM di Provinsi Jawa Barat mengalami perkembangan dilihat dari beberapa indikator diantaranya jumlah unit usaha mengalami peningkatan dari 910.00 unit (tahun 2013) menjadi 1.093.000 unit (tahun 2015) dengan jumlah investasi pada tahun 2013 sebesar 8.003.147 milyar rupiah, dan pada tahun 2015 sebesar 8.505.265 milyar rupiah. Selain itu jumlah tenaga kerja yang dapat terserap oleh UMKM juga mengalami peningkatan dari 15.007.695 orang (tahun 2013) menjadi 31.414.000 orang (tahun 2015).

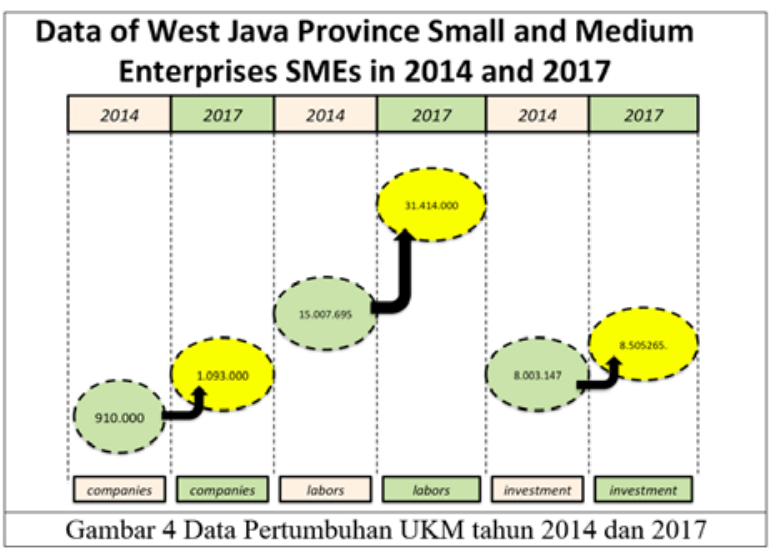

Sumber : Dinas Perindustrian dan Perdagangan Provinsi Jawa Barat (2017)

Akhir-akhir ini beberapa industri di Jawa Barat mengalami kerontokan seeperti industri rotan, tekstil, sepatu, keramik dan lain-lain. Penyebabnya antara lain adalah kesulitan bahan baku, meningkatnya harga-harga nilai tukar rupiah terhadap dollar dan lain-lain. Masalah daya saing dalam pasar lokal, nasional maupun internasional merupakan isu kunci dan tantangan yang tidak ringan bagi industri di berbagai daerah. Tanpa dibekali kemampuan dan keunggulan daya saing yang tinggi maka produk-produk yang dihasilkan industri tidak akan mampu menembus pasar. Bahkan dengan masuknya produk impor dapat mengancam posisi pasar 
domestik. Oleh karena itu, upaya meningkatkan daya saing dan membangun keunggulan kompetitif bagi produk-produk industri tidak dapat ditunda-tunda lagi dan sudah selayaknya menjadi perhatian berbagai kalangan, bukan saja bagi para pelaku usaha itu sendiri tetapi juga bagi aparat birokrasi, berbagai organisasi dan anggota masyarakat yang merupakan lingkungan kerja dari industry.

Orisinalitas atau keaslian penelitian ini adalah mencoba menguji dan menjelaskan Keunggulan Kompetitif Usaha Kecil dan Menegah (UKM) di Kabupaten Bandung berdasarkan Creation Theory of Entrepreneurial Action. Dalam hal ini ada tiga variabel yang terlibat yaitu Infrastruktur Teknologi Informasi (TI), Infrastruktur jalan berupa Aksesibilitas dan Aksi Kompetitif pada proses aksi kewirausahaan. Aksi kompetitif merupakan kemampuan UKM untuk mengeksplorasi dan mengeksploitasi peluang karena UKM telah memiliki Aksesibilitas dalam menjalankan operasi bisnisnya. Aksi Kompetitif juga berindikasi terhadap pemanfaatan infrastruktur TI dalam menciptakan aktifitas entrepreneurial untuk mencapai Keunggulan Kompetitif. Berdasarkan latar belakang penelitian maka judul disertasi ini adalah Pengaruh Infrastruktur Teknologi Informasi, Aksesibilitas pada Aksi Kompetitif di Pelaku Usaha Kecil dan Menengah di Kabupaten Bandung.

\subsection{Tujuan Penelitian}

Tujuan Penelitian ini adalah untuk mengetahui dan menganalisis pengaruh Infrastruktur Teknologi Informasi, Aksesibilitas Terhadap Aksi Kompetitif pada Industri Pakaian di Kabupaten Bandung.

\section{State of the Art (Novelty Penelitian)}

Orisinalitas dan Novelty penelitian ini adalah mencoba menguji dan menjelaskan Keunggulan Kompetitif Usaha Kecil dan Menegah (UKM) sektor industri pakaian di Kabupaten Bandung berdasarkan Creation Theory of Entrepreneurial Action. Dalam hal ini ada tiga variabel yang terlibat yaitu Infrastruktur Teknologi Informasi (TI), Infrastruktur jalan berupa Aksesibilitas dan Mobilitas, serta Aksi Kompetitif pada proses aksi kewirausahaan. Aksi kompetitif merupakan kemampuan UKM untuk mengeksplorasi dan mengeksploitasi peluang karena UKM telah memiliki Aksesibilitas dalam menjalankan operasi bisnisnya. Aksi Kompetitif juga berindikasi terhadap pemanfaatan infrastruktur TI dalam menciptakan aktivitas entrepreneurial untuk mencapai Aksi Kompetitif dan Keunggulan Kompetitif.

\section{Pengaruh Aksesibilitas Terhadap Aksi Kompetitif}

Infrastruktur memainkan peran penting dalam mendorong pertumbuhan ekonomi. Srinivasu \& Srinivasa (2013) mengemukakan bahwa pembangunan infrastruktur mampu merangsang aktifitas entrepreneurial sehingga akan mempengaruhi laju pertumbuhan ekonomi melalui aksi kompetitif. Peran pembangunan infrastruktur akan mempengaruhi isu ketimpangan sosial dan ekonomi di suatu wilayah. Infrastruktur mencakup seluruh fasilitas fisik dan non fisik, yang dibangun oleh perseorangan atau pemerintah guna mendukung terlaksananya kegiatan masyarakat termasuk aktifitas entrepreneurial yang membutuhkan akses dalam melaksanakan kegiatan usaha. Capineri \& Leinbach (2006) menyatakan bahwa era ekonomi global menjadikan usaha kecil dan menengah (UKM) sebagai tokoh utama dalam persaingan pasar bebas. Peran

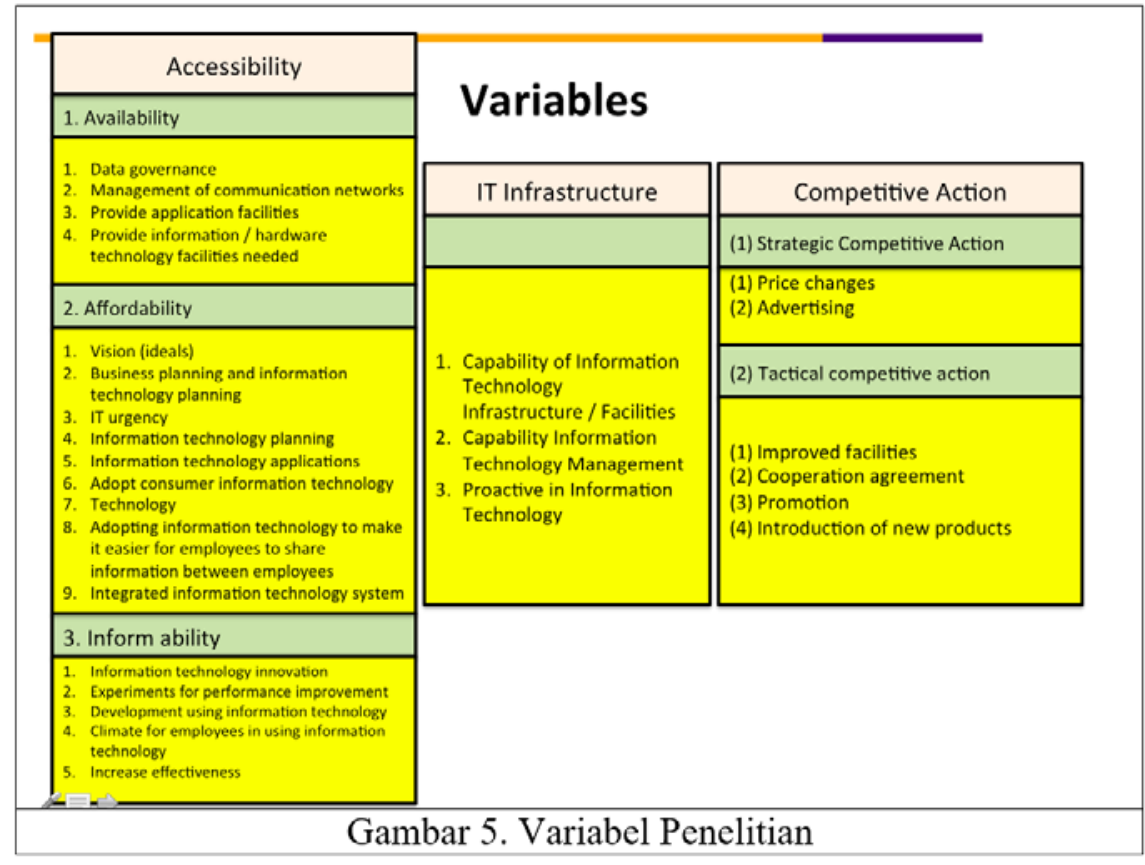




\section{Pengaruh Aksesibilitas , IT Dan Aksi Kompetitif Pada Usaha Mikro Kecil Dan Menengah (Zeis Zultaqawa, Mohammad Benny Alexandri, Muhammad Rizal, Nenden Kostini, Muhammad Donie Aulia)}

pemerintah pada konteks tersebut sangat penting sebagai bentuk dukungan pada UKM salah satunya adalah aksesibilitas (Andrevski, Brass, \& Ferrier, 2013).

\section{Pengaruh Infrastruktur Teknologi Informasi Terhadap Aksi Kompetitif}

Sehubungan dengan pengaruh TI pada perkembangan UKM, A. Ridwan Sinegar (2005) mengemukakan bahwa sejumlah UKM menyatakan bahwa penggunaan TI telah membawa perbaikkan yang jelas dalam hal penurunan biaya dan peningkatan keuntungan. Disebutkan bahwa TI memberikan manfaat bagi aksi kompetitif UKM sebagai berikut: 1) memperbaiki produktivitas dan kinerja, 2) pengawasan operasi internal yang lebih besar, 3) kemungkinan caracara baru dalam pengelolaan, 4) kemungkinan bentuk organisasi baru, 5) nilai tambah terhadap paket produk/layanan dan 6) membuka pasar yang jauh.

Menurut Turban, et.all (2001) Lingkungan, organisasional dan faktor teknologi membuat lingkungan persaingan bisnis yang tinggi, di mana faktor-faktor ini cepat berubah, yang kadang-kadang caranya tidak dapat diprediksi. Akibat perubahan yang cepat ini, perusahaan perlu reaksi yang cepat dalam menghadapi masalah dan peluang yang dihasilkan dari lingkungan bisnis yang baru tersebut (yang berfokus pada konsumen). Respon dapat juga merupakan aktivitas yang mengekploitasi peluang yang diciptakan oleh kondisi yang berubah. Kebanyakan aktivitasaktivitas respon ini dapat difasilitasi dengan baik dengan teknologi informasi (TI). Dengan memiliki, menggunakan dan memanfaatkan teknologi informasi, aksi kompetitif perusahaan dapat merespon perubahan lingkungan yang terjadi melalui beberapa kegiatan, antara lain: Sistem strategi memberikan perusahaan keuntungan, fokus pada memberikan layanan pelanggan, meningkatkan produktivitas dan kualitasnya, menstrukturisasi proses bisnis, strategi untuk memproduksi produk dan jasa yang telah disesuaikan, aliansi bisnis. Berdasarkan penjelasan diatas, hipotesis yang diajukan dalam penelitian ini adalah:

\section{Hipotesis}

H1: Infrastruktur Teknologi Informasi berpengaruh signifikan terhadap Aksi Kompetitif

H2: Aksesibilitas berpengaruh signifikan terhadap Aksi Kompetitif

\section{TINJAUAN PUSTAKA}

Grand theory penelitian ini adalah Resources Based View berdasarkan bidang ilmu Manajemen Strategis (David \& Carolina, 2011; Rumelt et al., 1991; Teece, 2007; Teece, Pisano, \& Shuen, 1997; Wernerfelt, 1984).
Hal ini berdasarkan pendapat Porter (1996), Hoskisson et al. (1999); Furrer (2008); dan Chen et al. (2010) yang menyatakan bahwa menciptakan Keunggulan Kompetitif adalah tujuan utama Manajemen Strategis. Pernyataan menciptakan Keunggulan Kompetitif dalam Kewirausahaan berkaitan dengan Creation Theory of Entrepreneurial Action dari Alvarez and Barney (2007). Teori ini berpandangan bahwa peluang entrepreneurial diciptakan dari proses pembelajaran bukan ditemukan (discovery) (Alvarez \& Barney, 2007). Entrepreneurial Action ditentukan oleh aksi-aksi pelaku UKM dalam menciptakan inovasi untuk mencapai Keunggulan Kompetitif. Aksi tersebut berupa kapabilitas yang berorientasi pada pencapaian persaingan yang kompetitif di pasar, konsep tersebut membentuk perilaku yang disebut Aksi Kompetitif.

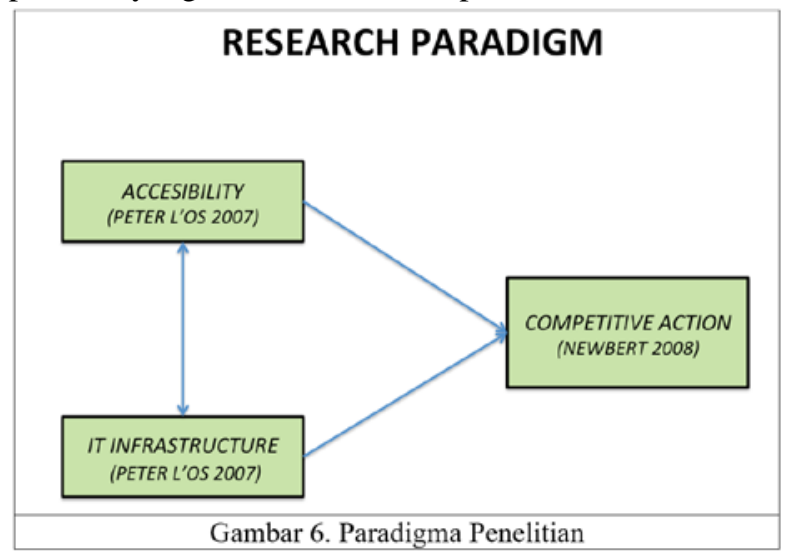

Penelitian tentang aksesibilitas dan mobilitas terhadap keunggulan kompetitif yang berdampak terhadap persaingan suatu usaha, Menurut Taylor (1998) sebuah jaringan dapat diartikan merupakan sebuah pengaturan terhadap jalur-jalur yang saling berhubungan, dimana obyek dapat berpindah dari satu titik ke titik lainnya. Jaringan yang dibangun oleh perusahaan yang bertujuan untuk memperluas daerah operasi dalam melakukan penjualan dan penyaluran distribusi. Perluasan pasar sangat dibutuhkan guna menunjang strategic competitiveness dan keunggulan kompetitif dari perusahaan (Paley, 1994). Dengan memiliki jaringan pemasaran perusahaan dapat mengetahui seberapa luas dan optimalnya sebuah titik jaringan. Disamping berguna untuk manajemen dan tenaga penjual dengan memiliki jaringan pemasaran maka proses transportasi dalam rangka menghantarkan barang kepada konsumen menjadi lebih efektif dan efisien. Ada konsumen yang hanya dapat menerima barang pada waktu tertentu saja karena kesibukannya. Dengan menggunakan akses yang ada maka efektivitas dan efisiensi penghantaran barang dapat ditingkatkan (Cooper, 1994:306). 


\section{HASIL DAN DISKUSI}

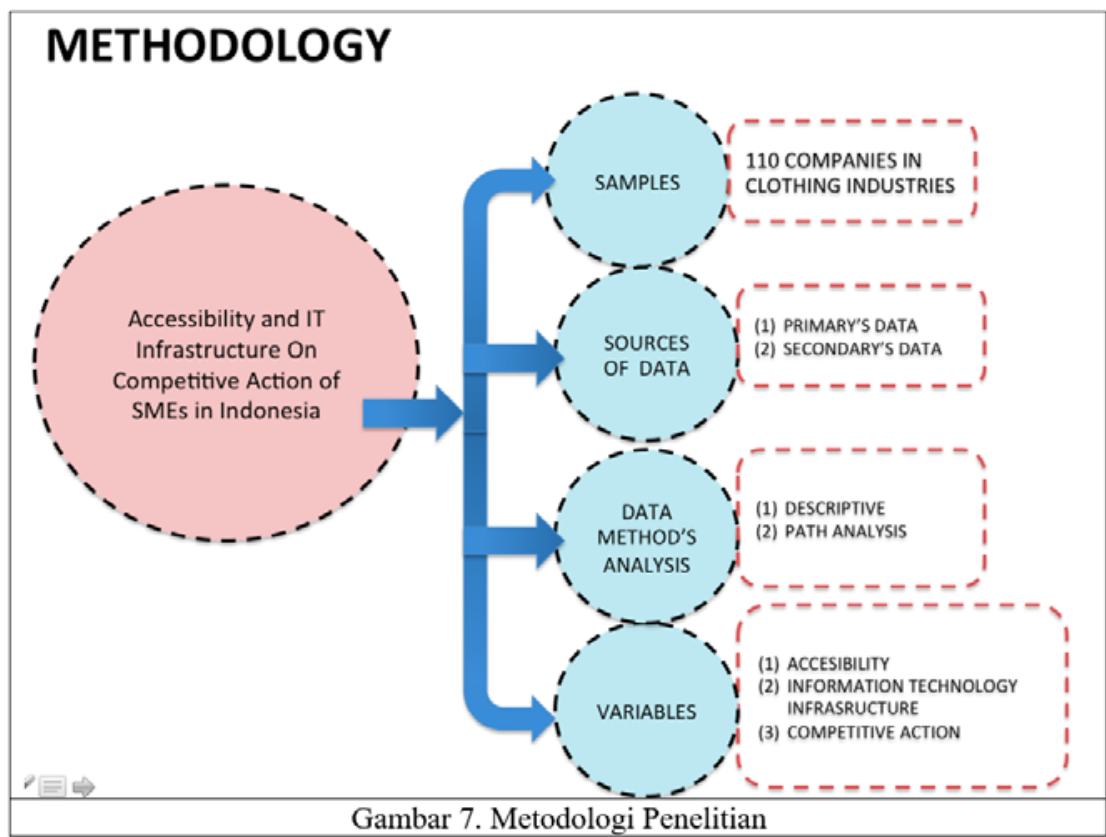

Penelitian ini menggunakan sampel sebanyak 300 perusahaan di bidang pakaian. Sumberdata adalah data primer dan sekunder. Data primer adalah melakukan wawancara kepada pihak pemerintah. Wawancara dilakukan kepada :

1. Dinas UKM Kabupaten Bandung

2. Pengusaha yang dijadikan sampel untuk wawancara

Data sekunder ditujukan berupa kuesioner kepada pemiliki usaha di bidang pakaian di Kabupaten Bandung.

Analisis data dengan menggunakan analisis deskriptif dan analisis Path Analisis.

Hasil dari olah data adalah sebagai berikut:

Model dari penelitian :

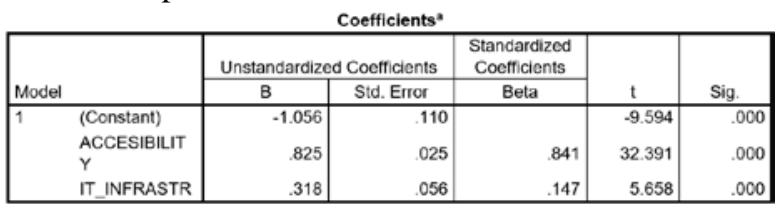

$$
\mathrm{Y}=-1.056+0.825 \mathrm{X} 1+0.318 \mathrm{X} 2+\mathrm{e}
$$

Untuk membuktikan hipotesis yang telah dilakukan, maka diperoleh hasil bahwa :

Aksesibilitas memiliki pengaruh positif kepada aksi kompetitif, dengan nilai signifikan kurang dari 0.05 IT Infrastruktur memiliki pengaruh positif kepada aksi kompetitif, dengan nilai signifikan kurang dari 0.05

Besarnya pengaruh kedua aksesibilitas dan IT Infrastruktur adalah sebesar 0.918 atau 91.8 persen, yang artinya nilainya sangat erat pengaruhnya.

Model Summary
\begin{tabular}{|l|c|r|r|r|}
\hline Model & R & R Square & $\begin{array}{c}\text { Adjusted R } \\
\text { Square }\end{array}$ & $\begin{array}{c}\text { Std. Error of } \\
\text { the Estimate }\end{array}$ \\
\hline 1 & $.958^{\mathrm{a}}$ & .918 & .918 & .16528 \\
\hline
\end{tabular}

Pengaruh antara aksesibilitas kepada IT Infrastruktur adalah sebesar 0.591 atau 59.1 persen yang artinya pengaruh keduanya sangat erat.

\section{Model Summary}

\begin{tabular}{|l|r|r|r|r|}
\hline Model & $\mathrm{R}$ & $\mathrm{R}$ Square & $\begin{array}{c}\text { Adjusted R } \\
\text { Square }\end{array}$ & $\begin{array}{c}\text { Std. Error of } \\
\text { the Estimate }\end{array}$ \\
\hline 1 & $.954^{\mathrm{a}}$ & .909 & .909 & .17366 \\
\hline
\end{tabular}

Besarnya pengaruh antara aksesibilitas pada aksi kompetitif adalah sebesar 90,9\%.

Model Summary

\begin{tabular}{|l|l|r|r|r|}
\hline Model & R & R Square & $\begin{array}{c}\text { Adjusted R } \\
\text { Square }\end{array}$ & $\begin{array}{c}\text { Std. Error of } \\
\text { the Estimate }\end{array}$ \\
\hline 1 & $.793^{a}$ & .629 & .628 & .35128 \\
\hline
\end{tabular}

Besarnya pengaruh Infrastruktur IT pada aksi kompetitif adalah sebesar $62,8 \%$

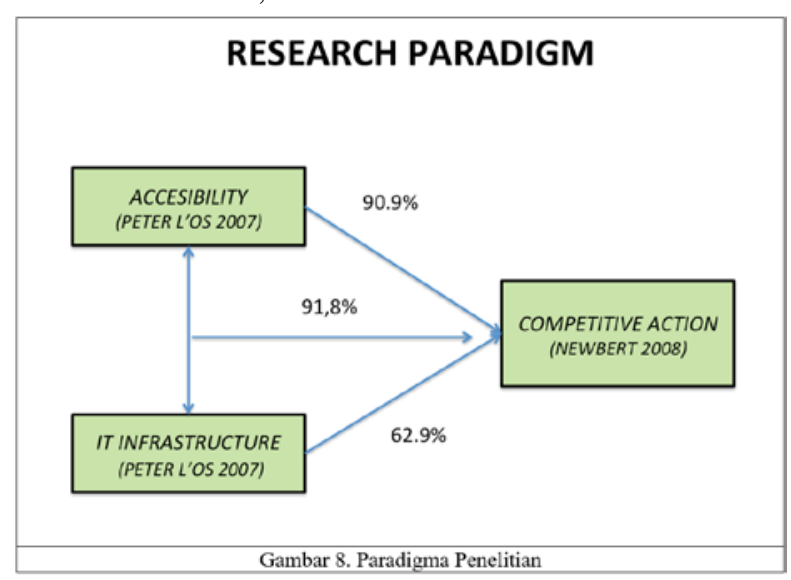




\section{Hubungan antar variable :}

Hubungan antara IT Infrastruktur pada aksesibilitas adalah sebesar 0.769. hubungan antara Hubungan antara IT pada aksi kompetitif adalah sebesar 0.954

Dari keduanya dapat disimpulkan bahwa terjadi hubungan erat antara ketiga variable.
9. Tata kelola Data, pengelolaan jaringan komunikasi , menyediakan fasilitas aplikasi, menyediakan fasilitas teknologi informasi/hardware yang diperlukan dianggap telah baik dilakukan oleh UKM di Kabupaten Bandung

10. Visi, perencanaan visi (cita-cita), perencanaan bisnis dan perencanaan teknologi informasi,

\begin{tabular}{|ll|r|r|r|}
\hline & & $\begin{array}{c}\text { CCCESIBILIT } \\
\text { Y }\end{array}$ & IT_INFRASTR & $\begin{array}{c}\text { COMPETTIVE } \\
\text { ACTION }\end{array}$ \\
\hline ACCESIBILITY & Pearson Correlation & 1 & $.769^{* *}$ & $.954^{* *}$ \\
& Sig. (2-tailed) & & .000 & .000 \\
& $\mathrm{~N}$ & 300 & 300 & 300 \\
\hline IT_INFRASTR & Pearson Correlation & $.769^{* *}$ & 1 & $.793^{* *}$ \\
& Sig. (2-tailed) & .000 & & .000 \\
& $\mathrm{~N}$ & 300 & 300 & 300 \\
\hline COMPETTIVE_AC & Pearson Correlation & $.954^{* *}$ & $.793^{* *}$ & 1 \\
TION & Sig. (2-tailed) & .000 & .000 & 300 \\
& $\mathrm{~N}$ & 300 & 300 & \\
&
\end{tabular}

Hasil dari penelitian ini adalah:

1. Pembangunan IT Infrastruktur semakin penting untuk disiapkan oleh pemerintah bagi UMKM untuk meningkatkan aksi kompetitifnya.

2. Aksi kompetitif bagi UKM industry pakaian menjadi semakin penting

3. Aksesibilitas UKM merupakan factor penting,khususnya bagi UKM industry pakaian

4. Kombinasi pembangunan IT Infrasruktur dan aksesibilitas akan meningkatkan aksi kompetitif UKM

5. TI memberikan manfaat bagi aksi kompetitif UKM sebagai berikut: 1) memperbaiki produktivitas dan kinerja, 2) pengawasan operasi internal yang lebih besar, 3) kemungkinan cara-cara baru dalam pengelolaan, 4) kemungkinan bentuk organisasi baru, 5) nilai tambah terhadap paket produk/layanan dan 6) membuka pasar yang jauh.

6. Aksesibilitas yang dapat dibangun pemerintah berupa jalan, baik jalan utama maupun jalan sebagai pendukung.

7. Aksi kompetitif merupakan kemampuan UKM untuk mengeksplorasi dan mengeksploitasi peluang karena UKM telah memiliki Aksesibilitas dalam menjalankan operasi bisnisnya. Aksi Kompetitif juga berindikasi terhadap pemanfaatan infrastruktur TI dalam menciptakan aktifitas entrepreneurial untuk mencapai Keunggulan Kompetitif.

8. Pengaruh antara IT Infrastruktur dan aksesibilitas adalah sebesar 59\%, yang artinya pengaruh antara keduanya juga sangat erat. urgensi IT, perencanaan teknologi informasi, aplikasi teknologi informasi, mengadopsi teknologi informasi keinginan konsumen, teknologi, mengadopsi teknologi informasi untuk memudahkan pegawai berbagi informasi antar pegawai, terintegrasi sistem teknologi informasi telah dilakukan oleh Pemerintah dalam mendukung UKM di Kabupaten Bandung

\section{KESIMPULAN}

1. Terdapat pengaruh aksesibilitas dan aksi kompetitif sebesar $90.9 \%$

2. Terdapat pengaruh IT Infrastruktur dan aksi kompetitif sebesar $62.9 \%$

3. Terdapat penagruh yang kuat antara aksesibilitas dan IT infrastruktur pada aksi kompetitif sebesar 91,8\%.

\section{SARAN}

1. Pemerintah Kabupaten Bandung meningkatkan infrastruktur IT di Kabupaten Bandung.

2. Aksesibilitas harus menjadi prioritas Pemerintah dengan memudahkan semua bagian yang terkait dengan kemajuan UMKM.

\section{REFERENSI}

Apulu, I., \& Latham, A. (2009). Information and Communication Technology Adoption : Challenges for Nigerian SMEs. TMC Academic Journal. 
Alvarez, S. A., \& Barney, J. B. (2007). The entrepreneurial theory of the firm. Journal of Management Studies, 44(7), 1057-1063.

Andrevski, G., Brass, D. J., \& Ferrier, W. J. (2013). Alliance Portfolio Configurations and Competitive Action Frequency. Journal of Management. https://doi.org/10.1177/0149206313498901

Capineri, C., \& Leinbach, T. R. (2006). Freight transport, seamlessness, competitive advantage in the global economy. European Journal of Transport and Infrastructure Research, 6(1), 23-38.

Chen, M.-J., Smith, K. G., \& Grimm, C. M. (1992). Action Characteristics as Predictors of Competitive Responses. Management Science. https://doi.org/10.1287/mnsc.38.3.439

Chen, M. J., \& Miller, D. (2015). Reconceptualizing competitive dynamics: A multidimensional framework. Strategic Management Journal. https://doi.org/10.1002/smj.2245

Colin, M., Galindo, R., \& Hernández, O. (2015). Information and communication technology as a key strategy for efficient supply chain management in manufacturing SMEs. In Procedia Computer Science. https://doi.org/10.1016/j.procs.2015.07.152

Cooper, T. (1999). Creating an Economic Infrastructure for Sustainable Product Design. The Journal of Sustainable Product Design.

Davenport, \& Linder. (1994). Information management infrastructure: the new competitive weapon? 1994 Proceedings of the Twenty-Seventh Hawaii International Conference on System Sciences.

https://doi.org/10.1109/HICSS.1994.323420

David, F. R., \& Carolina, S. (2011). Strategic Management Concepts and Cases. Zeitschrift für Personalforschung. https://doi.org/10.1688/ZfP-2014-03-Rowold

Erumban, A. A., \& Das, D. K. (2016). Information and communication technology and economic growth in India. Telecommunications Policy. https://doi.org/10.1016/j.telpol.2015.08.006

Farhadi, M., Ismail, R., \& Fooladi, M. (2012). Information and Communication Technology Use and Economic Growth. PLOS ONE. https://doi.org/10.1371/journal.pone.0048903

Hitt, M. A., Ireland, R. D., \& Hoskisson, R. E. (2012). Strategic management cases: competitiveness and globalization. Cengage Learning.
Jung, H. J., Na, K. Y., \& Yoon, C. H. (2013). The role of ICT in Korea's economic growth: Productivity changes across industries since the 1990s. Telecommunications Policy. https://doi.org/10.1016/j.telpol.2012.06.006

Li, X. (2009). Information and Communication Technology in China. International Journal of Information and Communication Technology Education. https://doi.org/10.4018/jicte.2009041004

Porter, M. E. (1980). Competitive Strategy. Techniques for Analyzing Industries and Competitors: With a New Introduction. https://doi.org/10.1002/jsc.540

Porter, M. E. (1985a). Competitive Advantage: Creating and sustaining superior performance. The Free Press. https://doi.org/10.1182/blood-2005-114354

Porter, M. E. (1985b). Technology and Competitive Advantage. Journal of Business Strategy. https://doi.org/10.1108/eb039075

Rumelt, R. P., Schendel, D., \& Teece, D. J. (1991). Strategic management and economics. Strategic Management Journal, 12(2 S), 5-29. https://doi.org/10.1002/smj.4250121003

Salahuddin, M., \& Alam, K. (2016). Information and Communication Technology, electricity consumption and economic growth in OECD countries: A panel data analysis. International Journal of Electrical Power \& Energy Systems. https://doi.org/10.1016/j.ijepes.2015.11.005

Srinivasu, B., \& Srinivasa, R. (2013). Infrastructure Development and Economic growth: Prospects and Perspective. Journal of Business Management \& Social Sciences Research.

Teece, D. J. (2007). Explicating dynamic capabilities: The nature and microfoundations of (sustainable) enterprise performance. Strategic Management Journal. https://doi.org/10.1002/smj.640

Teece, D. J. (2012). Dynamic Capabilities: Routines versus Entrepreneurial Action. Journal of Management Studies. https://doi.org/10.1111/j.14676486.2012.01080.x

Teece, D. J., Pisano, G., \& Shuen, A. (1997). Dynamic capabilities and strategic management. Strategic Management Journal, 18(7), 509533. https://doi.org/10.1002/(SICI)10970266(199708)18:7<509::AIDSMJ882>3.0.CO;2-Z 
Teece, D., \& Leih, S. (2016). Uncertainty, Innovation, and Dynamic Capabilities: An Introduction. California Management Review, 58(4), 5-12. https://doi.org/10.1525/cmr.2016.58.4.5

$\mathrm{Vu}$, K. M. (2013). Information and communication technology (ICT) and singapore's economic growth. Information Economics and Policy. https://doi.org/10.1016/j.infoecopol.2013.08.0 02

Wernerfelt, B. (1984a). A resource-based view of the firm. Strategic Management Journal. https://doi.org/10.1002/smj.4250050207
Wernerfelt, B. (1984b). A Resource based view of the firm. Strategic Management Journal, 5(2), 171-180. https://doi.org/10.1002/smj.4250050207

Wernerfelt, B. (1984c). Consumers with differing reaction speeds, scale advantages and industry structure. European Economic Review, 24(2), 257-270. 